\title{
Determinants of Teenage Pregnancy in Rural Ethiopia
}

\author{
Kemal Nure Kawo* \\ Department of Statistics, College of Natural and Computational Science, \\ Madda Walabu University, Bale Robe, Ethiopia \\ Abate Tadesse Zeleke \\ Department of Statistics, College of Natural and Computational Science, \\ Madda Walabu University, Bale Robe, Ethiopia \\ Dereje Bekele Dessie \\ Department of Statistics, College of Natural and Computational Science, \\ Madda Walabu University, Bale Robe, Ethiopia
}

\begin{abstract}
Teenage pregnancy is a major health concern because it associated with higher morbidity and mortality for both mother and child. The general aim was to assess the determinants of teenage pregnancy in rural Ethiopia using 2252 teenagers of EDHS 2016 data. The data was analyzed using descriptiv(percentage and barcchart) and inferential statistics(logistic regression).The descriptive statistics revealed that $16.3 \%$ of the teenagers experienced teenage pregnancy and the highest teenage pregnancy were found in the rural area of Harari, Afar, Dire Dawa and Somali regional state of Ethiopia while the lowest was found in Ahmara, SNNPand Tigray regional state of Ethipia. The logistic regression showed that age at first sexual intercourse, marital status, education level, wealth index, knowledge about ovulary cycle, Current contraceptive use and region were signficantly affect teenage pregnancy in Ethiopia. Hence, the government and other cocerned body should work to create awareness and legal restriction on reproductive activity of teenagers to minimize the risk of teenage pregancy across the regional state of Ethiopia. Keywords: Teenage; pregnancy; Logistic Regression
\end{abstract}

DOI: $10.7176 / \mathrm{JHMN} / 68-02$

Publication date: November $30^{\text {th }} 2019$

\section{INTRODUCTION}

Teenage pregnancy is generally defined as a pregnancy in a woman who is 19 years of age or below(unintended pregnancy during adolescence). Teenage pregnancy is situation which involves female adolescents. Teenage female can be pregnant as early as age twelve or thirteen, although it is usually fourteen and older. According to the United Nations Population Fund (UNFPA 2013),"Pregnancies among girls less than 18 years of age have irreparable consequences". It violates the rights of girls, with life-threatening consequences in terms of sexual and reproductive health, and poses high development costs for communities, The World Health Organization estimates that the risk of death following pregnancy is twice as high for women aged 15-19 than for those aged 20-24. The maternal mortality rate can be up to five times higher for girls aged 10-14 than for women aged 20-24. Illegal abortion also holds many risks for teenage girls in areas such as sub-Saharan Africa. Worldwide, teenage pregnancy rates range from 143 per 1000 in some sub-Saharan African countries to 2.9 per 1000 in South Korea. Approximately 750,000 of 15-19 year olds become pregnant each year, according to American college of Obstetricians and Gynecologists, though many teenagers don't believe that they will get pregnant if they engage in sexual activity.

Teenage pregnancy remains a challenge requiring urgent resolution the world over (United Nations Population Fund, 2013). In 2014 the World Health Organization reported that 11 percent of all births were due to women aged 15-19 years(World Health Organization, 2014). Approximately 95 percent of teenage pregnancies occur in developing countries with 36.4 million women becoming mothers before age 18. Sub-Saharan Africa had the highest prevalence of teenage pregnancy in the world in 2013(United Nations Population Fund, 2013). The majority of countries with teenage pregnancy levels above 30 percent occur in sub-Saharan Africa(Loaiza and Liang, 2013).

Studies have explored the effect of household variables on teenage pregnancy in Nigeria, Kenya, and Lesotho showing household size and parents' marital status as significant predictors of teenage pregnancy(Ifeoma, 2008; Ugoji,2011). Recent studies on teenage pregnancy in the subcontinent have looked at individual level demographic, socio-economic and reproductive health knowledge and behaviour parameters(Nyakubega, 2010, Molosiwa \& Moswela, 2012, Nwogwugwu, 2013). This research has identified education and soci-economic status as consistent determinants of teenage pregnancy in sub-Saharan African countries.

The proportion of births that take place during adolescence is about 2 percent in china, 18 percent in latin America and carribean and more than 50 percent in sub saharan Africa. Half of all adolescent births just occur in 
seven countries:Bangladesh, Brazil, the democratic republic of Congo, Ethiopia, India, Nigeria, and the United states. If current trends continue, by 2030 , there will be 26 million more adolescent girls in the world. Most of them will live in Asia and the Pacific and sub-Saharan Africa, where they will face significantly higher risks of pregnancy compared to their counterparts in other regions.

The magnitude of the issue of adolescent pregnancy can be better understood by looking at evidence from household surveys such as the DHS on the percentage of women aged 20 to 24 who had a live birth by age 15 or 18. The greatest increase in pregnancy among adolescent girls less than 18 years of age over the next 20 years is likely to happen in sub-Saharan Africa . In Eastern and Southern Africa, the number of adolescent-girls pregnant could increase by 57 percent, from 4.7 million ( 0.9 million per year)to 7.4 million( 1.5 million per year). Addressing adolescent pregnancy and motherhood is a key component of UNFPA's work to uphold the rights of adolescents. UNFPA supports partnerships and advocacy efforts to raise awareness about child pregnancy, including its causes and consequences. The issue of adolescent fertility is important on both health and social grounds. Children born to very young mothers are at increased risk of sickness and death. Teenage mothers are more likely to experience adverse pregnancy outcomes and are more constrained in their ability to pursue educational opportunities than young women who delay childbearing (UNFPA and UNICEF, 2010).

\section{Statement of the Problem}

Latest statistics from the Ethiopia Demographic Health Survey indicate 13\% of women between the ages of 15 and 19 have already given birth, and $2 \%$ are pregnant with their first child. Most teen pregnancies occur in the context of early marriage. Teen pregnancies are more common in rural than urban areas $(15 \%$ and $5 \%$, respectively), and among women in the Afar (23\%) and Somali regions (19\%); compared to the capital, Addis Ababa (3\%). Teenage pregnancy and motherhood is a major health concern because of its association with higher morbidity and mortality for both mother and child. Childbearing during the teenage years frequently has adverse social consequences as well, particularly on educational attainment, because women who become mothers in their teens are more likely to decrease their education (CSA and ICF, 2016).

Some reports and study such as (Tafa et al. 2004, Bearinger et al, 2007, Tariku 2008, Assefa et al. 2015, CSA and ICF, 2016 and Girls Not Brides, 2017) have identified determinants of teenage pregnancy but most of them did not consider factors associated with it in the rural area clearly.

Generally the study answered the following research question:

$\checkmark$ What are the factors that determine teenage pregnancy in rural Ethiopia?

$\checkmark \quad$ What are the most significant factors determining teenage pregnancy in rural Ethiopia?

Objectives of the study

The general objective of the study is to assess the determinants of teenage pregnancy in rural Ethiopia.

To identify significant factors that determine the teenage pregnancy in rural Ethiopia.

\section{DATA AND METHODOLOGY}

\section{Description of Data}

The study used scondary source of data which is EDHS 2016(2009 E.C) to analysis of determinants of Teenage pregnancy in rural Ethiopia. The data was collected by Ethiopian Demographic and Health survey which is conducted from january18, 2016 to June, 2016 based on nationally representative sample.

\section{Study Variables}

\section{Response variable}

The response variable is teenage pregnancy status of women who aged 15-19 years. If the teenage women had a pregnancy that miscarried, aborted or ended in a stillbirth, currently pregnant and gave birth; coded as 1 , if not coded as 0 )

\section{Independet variables}

The predictor(independent) variables of the study are classified as: demographic and socio economic variables which are expected to have an impact on teenage pregnancy. The predictor variables included in the study are: Current contraceptive use, Age, Age first sexual intercourse, Educational level women, Knowledge about ovulary cycle, Region, Religion of women, Wealth index, Employment Status, Media exposure

\section{Sampling Techniques}

The sample for the 2016 EDHS was designed to provide population and health indicators at the national and regional levels. The sample design allow for specific indicators, such as teenage pregancy, to be assesed for each eleven Ethiopia's admistrattive regions:namely nine regional states(Tigray, Afar, Amhara, Oromia, Somali, Benishangul-Gumuz, SNNPR, Gambela,Harari) and Addis Ababa and Dire-Dawa).

The sample were selected using two stage stratified design and EAs were the sampling units for the first stage sampling. Each region was stratified into urban and rural areas, yielding 21 sampling strata. In the first stage , samples of 645EAs (22 in urban and 443 in rural area) were selected independently in each sampling stratum. In the second stage of selection, a fixed number of 28 households per EAs were selected with equal probability system 
of selection and atotal of 15683(5348 in urban and 10335 in rural area) women aged 15-49 were interviewed. For this study, total of 2252 women who aged 15-19 were included.

\section{Statistical Models}

In this study the data was analyized using binary logistic regression to assess effect of determinant factors and regional difference on teenage pregnancy.

\section{Logistic Regression Analysis}

Logistic regression model is a statistical technique for predicting the probability of an event, given a set of predictor variables. The binary logistic regression procedure empowers one to select the predictive model for dichotomous dependent variables. It describes the relationship between a dichotomous response variable and a set of explanatory variables. The explanatory variables may be continuous or discrete (McCullagh and Nelder, 1989). Binary response models are of major importance in the social sciences as well as in demography since many social phenomena are discrete or qualitative rather than continuous or quantitative in nature. In such studies, the logistic regression model has become the statistical model of choice (Agresti, 2007). For this study, the binary logistic regression model was used to investigate effect of predictors on the probability of the response variables (teenage pregnancy) ( $Y_{i j}$ ) Ethiopia which is defined as follows. $Y_{i j}$ takes a values 1 if the teenage experience pregnancy and 0 other wise. where:- $\mathrm{i}=1,2, \ldots \mathrm{n}, \mathrm{j}=1,2, \ldots \mathrm{M}$, where:- $\mathrm{n}$ is the number of sampled teenage. $\mathrm{M}$ is the number of region in Ethiopia.

Let us denote the proportion of success (experience teenage pregnancy)

$$
p\left(Y_{i}=1\right)=\pi_{i j} \quad p\left(Y_{i j}=1\right)=1-\pi_{i j}
$$

and $\mathrm{Y}_{\mathrm{i}} \sim \operatorname{Bernoulli}\left(\pi_{\mathrm{i}}\right)$

The logistic regression model is defined as follows. Let $\mathbf{X}_{\mathrm{nx}(\mathrm{k}+1)}$ denote the single level binary logistic regression data matrix of $\mathrm{k}$ predicator variables of the teenage pregnancy and $\boldsymbol{\beta}_{(\mathrm{k}+1) \mathbf{x} \mathbf{1}}$ be a vector of coefficients and given as:

$$
X=\left[\begin{array}{ccccc}
1 & x_{11} & x_{12} & \ldots & x_{1 k} \\
1 & x_{21} & x_{22} & \ldots & X_{2 k} \\
\vdots & \ldots & \ldots & \ldots & \vdots \\
1 & x_{n 1} & x_{n 2} & \ldots & x_{n k}
\end{array}\right] \quad \beta=\left[\begin{array}{c}
\beta_{o} \\
\beta_{1} \\
\vdots \\
\beta_{k}
\end{array}\right]
$$

$\mathrm{X}$-is the design matrix $\beta$ - is the vector of unknown coefficients of the covariates and intercept then, the logistic regression function is given as:

$$
\pi_{i}=\frac{\exp \left(\beta_{o}+\beta_{1} X_{i 1}+\beta_{2} X_{i 2}+\ldots+\beta_{k} X_{i k}\right)}{1+\exp \left(\beta_{o}+\beta_{1} X_{i 1}+\beta_{2} X_{i 2}+\ldots+\beta_{k} X_{i k}\right)}=\frac{\exp \left(X_{i}^{\prime} \beta\right)}{1+\exp \left(X_{i}^{\prime} \beta\right)}
$$

where:- $\pi_{\mathrm{i}} \llbracket \mathrm{i}=1,2, \ldots \mathrm{n} \rrbracket$ is the $\mathrm{i}^{\text {th }}$ probability of experiencing teenage pregnancy given the vector of predictors (X)

By algebraic manipulation, the logistic regression equation can be written as in terms of an odds ratio:

$$
\begin{gathered}
\pi=\frac{P(y=1 / X i)}{1-p(y=1 / X i)}=\exp \left(\beta_{o}+\beta_{1} X_{1}+\beta_{2} X_{2}+\ldots .+\beta_{k} X_{k}\right)=\exp \left(X_{i}{ }^{\prime} \beta\right) \\
\log \left(\frac{P(y=1 / X i)}{1-p(y=1 / X i)}\right)=\log \left(\frac{\pi_{i}}{1-\pi_{i}}\right)=\beta_{o}+\beta_{1} X_{1}+\beta_{2} X_{2}+\ldots+\beta_{k} X_{k}=X_{i}{ }^{\prime} \beta
\end{gathered}
$$

where:- $i=1,2, \ldots, \mathrm{k}$

In case of categorical predictor variable, it is interpreted as the log-odds of experiencing teenage pregnancy given a category compared to the reference category (Dayton, 1992).

\section{RESULT AND DISCUSION}

\section{Descriptive Statistics}

\section{Socio-economic and demographic character}

The major socio-economic and demographic related characteristic of the respondents (Teenage) were presented in Table 1. Out of 2252 teenager, 366(16.3\%) of them were teenage pregnancy and motherhood whereas $1886(83.7 \%)$ of them were not. With regarding age at first sex of teenage, the highest percentages of teenage pregnancy $(57.60 \%)$ was observed in age group 8-14 and followed by $51.1 \%$ in the age group $15-19$.

Based on marital status of teenage, the percentage of teenage pregnancy and motherhood was the highest for those who were married (59.0\%) and the lowest for those who were single $(1 \%)$, while $30 \%$ for those who were divorced or widowed. 
Similarly, the percentage of teenage pregnancy vary across the religion of the respondent which is $10.5 \%$, $6.2 \%, 14.0 \%, 21.8 \%$ and $23.5 \%$ for Orthodox, Catholic, Protestant, Muslim and other religions respectively.

As the education level of teenage women increase the percentage of teenage pregnancy decrease. The percentage of teenage pregnancy based the education level is $34.0 \%, 11.5 \%$ and $6.7 \%$ for un educated, primary and secondary and above education level respectively.

There was also variation in percentages of teenage pregnancy based on current contraceptive usage of teenage women. $15.1 \%$ of teenage women who did not use any contraceptive method were experienced teenage pregnancy while $34.0 \%$ of them contraceptive users.

Similarly, the percentages of teenage pregnancy vary based on teenage knowledge of ovulary cycle; the percentage of teenage pregnancy for those who know about ovulary cycle was higher $(24.8 \%)$ than those who did not know about ovulary cycle (17.7\%).

Percentage of teenage pregnancy based on current working status of women shows that $17.0 \%$ of teenage women those who did not work were pregnant where as $13.8 \%$ of those who were workings are pregnant.

Those teenage women who had no mass media were more exposed (17.0\%) to teenage pregnancy than those who had mass media $(13.8 \%)$. Teenage pregnancy was higher $(21.5 \%)$ for teenage women who were poor than those who middle (18.4\%) and Rich $(8.2 \%)$.

Teenage pregnancy distribution across regional state of Rural Ethiopia

Table 2 revealed that teenage pregnancy distribution of women across the regional state of Ethiopia in the rural area. The highest proportion of teenage pregnancy were found in Harari $(26.0 \%)$, Afar (25.8\%), Dire Dawa (25.5\%), Somali (21.2\%) and the lowest in proportion were found in Amhara (8.9\%) and SNNPR (11.0\%), while the proportion was in Tigray (12.4\%), Benishangul (14.5\%), Oromia (18.1\%) and Gambela (19.6\%).

Table 2. column chi-square test showed that there is significant association between teenage pregnancy, and regional state of Ethiopia in the rural area at $5 \%$ level of significance. The variable age at first sex, marital status, education level, current contraceptive use, knowledge about ovulary cycle, exposure to mass media and wealth index were significantly associated at $5 \%$ level of significance where current working status was not significant.

Figure 1 show that teenage pregnancy distribution across the age interval at first sex of teenage. $57.58 \%$ of teenage who had their first sexual intercourse in the age interval 8-14 were experienced teenage pregnancy, and $48.87 \%$ of those who had their first sexual intercourse in the age interval $15-19$ were exposed to teenage pregnancy. It revealed that more than half percent of teenage who had their first sexual intercourse in their early age (8-14) were more likely exposed to teenage pregnancy.

Figure 2 revealed that teenage pregnancy distribution of teenage over their regional state. The highest and the lowest proportion of teenage pregnancy were found in Harari (26\%), Afar (25.7\%), Dire Dawa $(25.45 \%)$ and Amhara (8.9\%), SNNP (10.8\%), Tigray (12.4\%) $\mathrm{r}$ regional state of Ethiopia respectively. While other regional state's teenage pregnancy proportion were found in between.

\section{Inferential statistics}

\section{Binary Logistics Regression of Teenage pregnancy and motherhood}

The statistical significance of each determinant of Teenage pregnancy assessed based on Wald test as shown in Table 3. The result revealed that age at first sex, marital status, educational level, using contraceptive, knowledge about ovulary cycle, wealth index and region were found significant factors that affect teenage pregnancy at $5 \%$ level of significance.

The binary logistic regression revealed that age at first sexual intercourse was found significant determinant of teenage pregnancy at $5 \%$ level of significance and the odds of teenage who had their first sexual intercourse in the age 8-14 was 1.62 time more likely than those in the age group 15-19 in experiencing teenage pregnancy, keeping all other factors constant.

Marital status of the teenage was found a significant factor of teenage pregnancy at $5 \%$ level of significance and the odds of teenage that were single were .81 times less likely than widowed and divorced teenagers in experiencing teenage pregnancy, keeping other factors constant. While teenage who were married were 2.87 times more likely to experience than those who were widowed and divorced, keeping other factor constant.

Education level of teenagers (Primary and secondary and above education) were found significant determinants of teenage pregnancy and at $5 \%$ level of significance and the odds teenagers having who completed primary education was 0.47 times less likely than those who had not education in teenage pregnancy, keeping all other factors constant. Additionally, the odds of teenagers who completed secondary and above education were 0.43 times less likely than those who had had no education level in teenage pregnancy, holding other factors constant.

Current use of contraceptive of teenagers also significantly determine teenage pregnancy at $5 \%$ level of significance and the odds of those teenagers who were currently not use any contraceptive 1.633 times more likely than those who were currently using contraceptive in experiencing teenage pregnancy, keeping other factors constant.

Similarly, Knowledge about ovulary cycle of teenagers was found significantly affect teenage pregnancy at 
$5 \%$ level of significance and the odds of teenage pregnancy for those who know about ovulary cycle was 0.324 times less likely than those who did not know about ovulary cycle, fixing all other factors constant.

Wealth index (poor, middle and rich) were found significantly affect teenage pregnancy at $5 \%$ level of significance. The odds of teenagers who were poor and middle were 1.508 and 1.88 times more likely than those who were rich in experiencing teenage, respectively, fixing all other factors constant.

Finally, living in the regional state of Ethiopia (Oromia, Somali, Benishangul, SNNP, Gambela and Dire Dawa) were significantly determine teenage pregnancy relative living in Afar at 5\% level of significance and the odds of teenage pregnancy of living in Oromia, Somali, Benishangul, SNNP, Gambela and Dire Dawa were 3.48, $2.49,2.44,5.10,2.10$ and 4.62 times more likely than those who were living in Afar, respectively, keeping other factors constant.

\section{CONCLUSION AND RECOMMENDATION}

\section{Conclusion}

The aim of this study was to investigate factors associated in Teenage pregnancy in rural Ethiopia based on sample of 2016 EDHS data. The study used descriptive (percentage and bar chart) and inferential (binary logistic regression) statistics.

The descriptive result revealed that out of 2252 respondents, $366(16.3 \%)$ of them experience teenage pregnancy and $1886(83.7 \%)$ of them were not experience teenage pregnancy in the rural Ethiopia. The chi-square test of association also revealed that there was a significant association between predictors (Age at first sexual intercourse, marital status, education level, knowledge on ovulary cycle, use contraceptive, wealth index, religion, media exposure and region) and teenage pregnancy and motherhood at $5 \%$ level of significance.

\section{Recommendation}

Based on the finding of this study the following recommendation is forwarded.

Government and concerned body should work on the awareness of teenagers in order to enhance their knowledge about reproductive health and fertility

Government and health related office should create-intensified awareness creation targeted to increase teenagers/adolescent/ understanding of teenage pregnancy in order to reduce risk of teenage pregnancy and motherhood.

Education level of mothers plays an important role in teenage pregnancy. Thus, education sectors need to focus on sustaining women education and create awareness about the reproductive health to minimize teenage pregnancy and motherhood.

Age at first sexual intercourse and marital status plays an important role in teenage pregnancy. Thus, government and concerned body should set legal restriction and check the implementation of it as to minimize risk of teenage pregnancy.

\section{REFERENCES}

Adebayo O. (2014); Factors associated with teenage pregnancy and fertility in Nigeria. Journal of Economics and Sustainable Development. www.iiste.org. ISSN 2222-1700 (Paper) ISSN 2222-2855 (Online) Vol.5, No.2, 2014

Agresti A. (2007). An introduction to categorical data analysis (2 ${ }^{\text {nd }}$ Ed.). New York: John Wiley \& Sons

Assefa Beyene,Abiyou Muhiye,Yenenh Getachew,Damen Haile,Millard Derbew,Dereje Mamo,Fikre Enkuselassie(2015).Assesment of the mangnitude of teenage pregnancy and its associated factors among teenage females visiting Asosa general Hospital: Ethiop Med J,2015,supp.2

Bearinger LH, Sieving RE, Ferguson J, Sharma V. Global perspectives on the sexual and reproductive health of adolescents:patterns, prevention and potential. The lancet 2007;369:1220-31.

Bursik, R. J. (1988). Social disorganization and theories of crime and delinquency: Problems and prospects*. Criminology, 26(4), 519-552.

Clifton, D., Hervish, A. (2013). The World's Youth 2013 Data Sheet. Washington DC: Population Reference Bureau.

CSA-Central Statistical Agency and ICF. (2016). Ethiopia Demographic and Health Survey 2016: Key Indicators Report. Addis Ababa: CSA and Rockville, Maryland: ICF.

Dayton, C.M. 1992. Logistic Regression Analysis. Department of Measurement, Statistics and Evaluation, University of Maryland

Darroch, JE, et al. (2016). Adding it Up: Costs and Benefts of Meeting the Contraceptive Needs of Adolescents. New York: Guttmacher Institute.

Girls Not Brides. (2017). Child Marriage Around the World: Ethiopia. Retrieved 11 July 2017 from http://www.girlsnotbrides.org/childmarriage/ethiopia/.

Guttmacher Institute. (2017). Adding It Up: Investing in Contraception and Maternal and Newborn Health, 2017. Fact sheet. Retrieved 5 July 2017 from: https://www.guttmacher.org/fact-sheet/adding-it-up-contraception- 
mnh-2017.

Ifeoma, G. F. (2008). The effect of household characteristics on adolescent childbearing in Lesotho. (Master of Arts), University of the Witwatersrand.

Ibrahim Isa Auba and Owoeye Gani(2012):Outcome of teenage pregnancy in the Niger Delta of Nigeria, Ethio JHealth Sci.vol.22

Kawachi, I., Subramanian, S. V. (2007). Neighbourhood influences on health. Journal of epidemiology and community health, 61(1), 3-4. doi: 10.1136/jech.2005.045203

Kubrin, C. (2009). Social Disorganization Theory: Then, Now and in the Future. In Krohn (Ed.), Handbook on Crime and Deviance: Springer Science and Business Media.

Lenny Mushwana, Lydia Monareng, Solina Richter, Helene Muller (2015): Factors influencing the adolescent pregnancy rate in the Greater GiyaniMunicipality, Limpopo Province - South Africa; International Journal of Africa Nursing Sciences 2 (2015) 10-18

Loaiza, E., Liang, M. (2013). Adolescent Pregnancy: A Review of Evidence. New York: United Nations Population Fund.

MarÃ-a Navarro Paniagua, Ian Walker:Lancaster University and IZA(2012): The Impact of Teenage Motherhood on the Education and Fertility of their Children:iza dp no.6995

Mohd Azri Mohd Suan, MBBS*, Adibah Hanim Ismail, (2015) study A Review of teenage pregnancy research in Malaysia. Med J malaysia vol.70. 4; august 2105

Molosiwa, S., Moswela, B. (2012). Girl-pupil dropout in secondary schools in Botswana: Influencing factors, prevalence and consequences. International Journal of Business and Social Science, 3(7), 265-271.

Negussie Taffa, Francis Obare(2004) Pregnancy and child health outcomes among adolescents in Ethiopia. Ethiop.J.Health Dev. 2004;18(2):90-95

Nwogwugwu, N. C. (2013). Socio-demographic determinants of adolscent fertility in Zambia. (Masters of Arts), University of the Witwatersrand.

Ngonidzashe M. and Godfrey M. (2015): Factors Contributing to Teenage Pregnancies in a Rural Community of Zimbabwe: Journal of Biology, Agriculture and Healthcare www.iiste.org ISSN 2224-3208 (Paper) ISSN 2225-093X (Online) Vol.5, No.14, 2015

Nyakubega, P. (2010). Factors associated with adolescent pregnancies among secondary school students. a study from Tanga-Tanzania. Dar Es Salaam Medical Students’ Journal, 16(1), 31-34.

Ugoji, F. (2011). Parental marital status and peer influence as corelates of teenage pregnancy among female teens in south-South Nigeria. Gender and Behaviour, 9(2), 4125-4138.

United Nations Population Fund (UNFPA). 2007. Giving Adolescents today and tommow:breaking the cyle of adolescent pregnancy, New York;UNFPA 2007

UNFPA and UNICEF. 2010. Women's Children's Rights, New York: UNFPA.

United Nations Population Fund. (2013). Motherhood in Childhood: Facing the challenge of adolescent pregnancy. New York: UNFPA.

UNFPA (2013). "Adolescent Pregnancy, Areview of Evidence" Population and Development branch. Technical Devision. New.York: UNFPA.

UNFPA. (2017). "Adolescent pregnancy". Retrieved 4 July 2017 from: https://www.unfpa.org/adolescentpregnancy.

WHO-World Health Organization. (2014) Adolescent pregnancy. Fact sheet. Retrieved 6 July 2017 from: http://www.who.int/ mediacentre/factsheets/fs364/en/.

Yared Mekonnen, Daniel S. Telake and Endeshaw Wolde(2018): Adolescent childbearing trends and sub national variations in Ethiopia: a pooled analysis of data from six surveys. BMC Pregnancy and Childbirth (2018) 18:276, doi.org/10.1186/s12884-018-1917-8 
Table 1: Demographic and economic character vs teenage pregnancy

\begin{tabular}{|c|c|c|c|c|c|c|}
\hline \multirow{3}{*}{\multicolumn{2}{|c|}{ Variables }} & \multicolumn{4}{|c|}{ Pregnancy status } & \multirow{3}{*}{$\begin{array}{c}\text { Chi-square test } \\
\text { Pearson value } \\
\text { (sign.) }\end{array}$} \\
\hline & & \multicolumn{2}{|r|}{ No } & \multicolumn{2}{|r|}{ Yes } & \\
\hline & & \multirow{2}{*}{\begin{tabular}{|c|} 
Count \\
1557
\end{tabular}} & Percent (\%) & \multirow{2}{*}{\begin{tabular}{c|} 
Count \\
0
\end{tabular}} & Percent (\%) & \\
\hline \multirow{4}{*}{ Age at first sex } & Not had sex & & $100 \%$ & & $0 \%$ & \multirow{4}{*}{$\begin{array}{l}978.36 \\
\mathbf{( 0 . 0 0 0 )}\end{array}$} \\
\hline & $8-14$ & 70 & $42.4 \%$ & 95 & $57.6 \%$ & \\
\hline & $15-19$ & 259 & $48.9 \%$ & 271 & $51.1 \%$ & \\
\hline & Single & 1590 & $99.0 \%$ & 16 & $1.0 \%$ & \\
\hline \multirow[t]{4}{*}{ Current marital status } & Married & 222 & $41.0 \%$ & 319 & $59.0 \%$ & \multirow{3}{*}{$\begin{array}{c}1013.14 \\
(\mathbf{0 . 0 0 0 )}\end{array}$} \\
\hline & Widowed\& divorced & 73 & $69.5 \%$ & 32 & $30.5 \%$ & \\
\hline & Orthodox & 682 & $89.5 \%$ & 80 & $10.5 \%$ & \\
\hline & Catholic & 15 & $93.8 \%$ & 1 & $6.2 \%$ & \multirow{2}{*}{$\begin{array}{c}44.49 \\
(\mathbf{0 . 0 0 0})\end{array}$} \\
\hline \multirow[t]{4}{*}{ Religion } & Protestant & 388 & $86.0 \%$ & 63 & $14.0 \%$ & \\
\hline & Muslin & 787 & $78.2 \%$ & 219 & $21.8 \%$ & \multirow{5}{*}{$\begin{array}{l}170.55 \\
\mathbf{( 0 . 0 0 0 )}\end{array}$} \\
\hline & others & 13 & $76.5 \%$ & 4 & $23.5 \%$ & \\
\hline & No education & 361 & $66.0 \%$ & 186 & $34.0 \%$ & \\
\hline \multirow[t]{2}{*}{ Educational level } & Primary & 1219 & $88.5 \%$ & 159 & $11.5 \%$ & \\
\hline & secondary and above & 305 & $93.3 \%$ & 22 & $6.7 \%$ & \\
\hline \multirow{2}{*}{ contraceptive use } & No method & 1792 & $84.9 \%$ & 319 & $15.1 \%$ & \multirow{2}{*}{$\begin{array}{c}34.72 \\
(\mathbf{0 . 0 0 0})\end{array}$} \\
\hline & Modern & 93 & $66.0 \%$ & 48 & $34.0 \%$ & \\
\hline \multirow{2}{*}{ Know ovulatory cycle } & know & 1403 & $87.1 \%$ & 208 & $12.9 \%$ & \multirow{2}{*}{$\begin{array}{c}47.55 \\
(\mathbf{0 . 0 0 0 )}\end{array}$} \\
\hline & Not know & 482 & $75.2 \%$ & 159 & $24.8 \%$ & \\
\hline \multirow{2}{*}{ Has Mass media. } & No & 1355 & $82.3 \%$ & 291 & $17.7 \%$ & \multirow{2}{*}{$\begin{array}{c}8.57 \\
\mathbf{( 0 . 0 0 3 )}\end{array}$} \\
\hline & Yes & 530 & $87.5 \%$ & 76 & $12.5 \%$ & \\
\hline \multirow{3}{*}{ Currently working } & No & 1460 & $83.0 \%$ & 299 & $17.0 \%$ & \multirow{3}{*}{$\begin{array}{c}2.92 \\
(\mathbf{0 . 0 8 9})\end{array}$} \\
\hline & Yes & 425 & $86.2 \%$ & 68 & $13.8 \%$ & \\
\hline & poor & 849 & $78.5 \%$ & 233 & $21.5 \%$ & \\
\hline \multirow[t]{2}{*}{ Wealth index } & middle & 302 & $81.6 \%$ & 68 & $18.4 \%$ & \multirow{2}{*}{$\begin{array}{l}60.90 \\
(\mathbf{0 . 0 0 )}\end{array}$} \\
\hline & Rich & 734 & $91.8 \%$ & 66 & $8.2 \%$ & \\
\hline
\end{tabular}

Table2: Teenage pregnancy distribution across regional state of Ethiopia

\begin{tabular}{|c|c|c|c|c|c|c|}
\hline \multirow[t]{3}{*}{ Variable } & \multirow{3}{*}{ Categories } & \multicolumn{4}{|c|}{ Pregnancy status } & \multirow{3}{*}{$\begin{array}{c}\text { Chi-square test } \\
\text { Pearson value } \\
\text { (Sign.) }\end{array}$} \\
\hline & & \multicolumn{2}{|c|}{ No } & \multicolumn{2}{|c|}{ Yes } & \\
\hline & & Count & Percent (\%) & Count & Percent (\%) & \\
\hline \multirow{10}{*}{ Region } & Tigray & 283 & $87.6 \%$ & 40 & $12.4 \%$ & \multirow{10}{*}{$\begin{array}{c}52.70 \\
\mathbf{( 0 . 0 0 0 )}\end{array}$} \\
\hline & Afar & 167 & $74.2 \%$ & 58 & $25.8 \%$ & \\
\hline & Amhara & 277 & $91.1 \%$ & 27 & $8.9 \%$ & \\
\hline & Oromia & 290 & $81.9 \%$ & 64 & $18.1 \%$ & \\
\hline & Somali & 190 & $78.8 \%$ & 51 & $21.2 \%$ & \\
\hline & Benishangul & 171 & $85.5 \%$ & 29 & $14.5 \%$ & \\
\hline & SNNPR & 298 & $89.0 \%$ & 37 & $11.0 \%$ & \\
\hline & Gambela & 111 & $80.4 \%$ & 27 & $19.6 \%$ & \\
\hline & Harari & 57 & $74.0 \%$ & 20 & $26.0 \%$ & \\
\hline & Dire Dawa & 41 & $74.5 \%$ & 14 & $25.5 \%$ & \\
\hline
\end{tabular}


Figure 1: Bar chart of teenage pregnancy distribution over age at first sex interval.

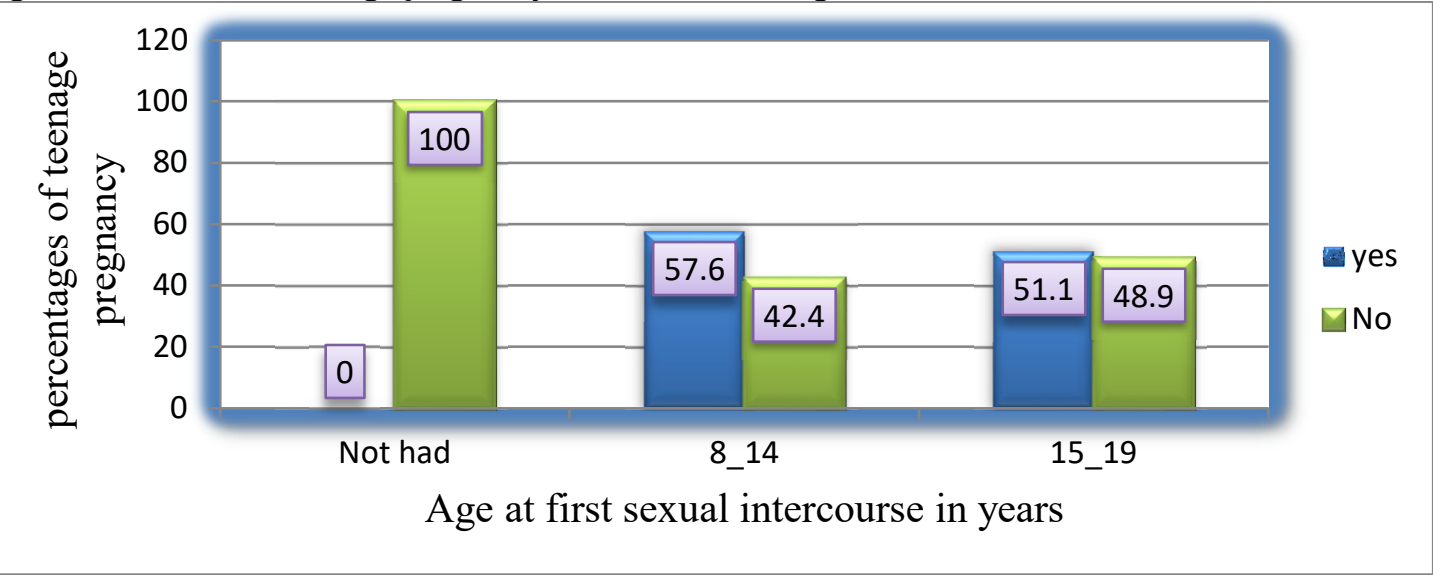

Figure 2: Teenage pregnancy and motherhood distribution in rural regional state of Ethiopia

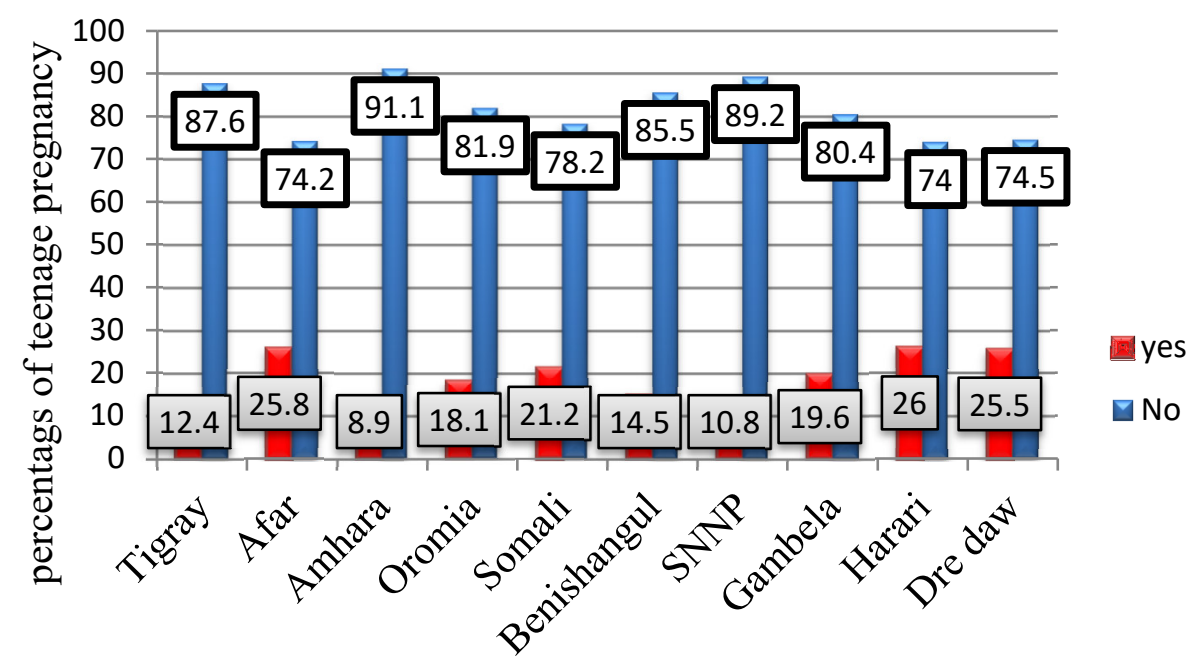

\section{Regional State of Ethiopia}


Table 3: Determinant factors of teenage pregnancy in Ethiopia

\begin{tabular}{|c|c|c|c|c|c|c|c|c|}
\hline \multirow{2}{*}{\multicolumn{2}{|c|}{$\begin{array}{l}\text { Independent variables } \\
\text { Categories }\end{array}$}} & \multirow{3}{*}{$\begin{array}{l}\text { Coef. } \\
-6.675\end{array}$} & \multirow{3}{*}{$\begin{array}{l}\text { S.E. } \\
1.062 \\
\end{array}$} & \multirow{3}{*}{$\begin{array}{l}\text { Wald } \\
39.438 \\
\end{array}$} & \multirow{3}{*}{$\begin{array}{l}p- \\
\text { value } \\
0.00\end{array}$} & \multirow{3}{*}{$\begin{array}{l}\text { OR } \\
0.0012\end{array}$} & \multicolumn{2}{|c|}{ 95\% C.I for OR } \\
\hline & & & & & & & \multirow{2}{*}{$\begin{array}{l}\text { Lower } \\
0.0001\end{array}$} & \multirow{2}{*}{$\begin{array}{l}\text { Upper } \\
0.010\end{array}$} \\
\hline Age at first sex (Ref:15-19) & Not had & & & & & & & \\
\hline & $8-14$ & .477 & .215 & 4.928 & 0.026 & 1.612 & 1.058 & 2.456 \\
\hline \multirow{2}{*}{$\begin{array}{lll}\begin{array}{l}\text { Marital } \\
\text { divorced) }\end{array} & \text { status } \quad \text { (Ref: }\end{array}$} & Sngle & -0.214 & .428 & 0.25 & 0.617 & .807 & .348 & 1.868 \\
\hline & Married & 1.055 & .261 & 16.322 & 0.000 & 2.871 & 1.721 & 4.790 \\
\hline \multirow{2}{*}{$\begin{array}{l}\text { Educationlevel } \\
\text { (Ref:Noteducated) }\end{array}$} & Primary & -.754 & .194 & 15.132 & 0.000 & .470 & .3218 & .688 \\
\hline & $>=2$ ndary & -.832 & .367 & 5.153 & 0.023 & .435 & .2119 & .893 \\
\hline $\begin{array}{l}\text { Use contraceptive (Ref: } \\
\text { yes) }\end{array}$ & No & .490 & .2448 & 4.00 & 0.045 & 1.633 & 1.011 & 2.639 \\
\hline $\begin{array}{l}\text { Know.Ovulary cy. } \\
\text { (Ref: not know) }\end{array}$ & Know & -1.124 & .191 & 34.692 & 0.000 & .324 & .2234 & .4722 \\
\hline \multirow{2}{*}{$\begin{array}{l}\text { Wealth index } \\
\text { (Ref: Rich) }\end{array}$} & poor e & .4112 & .236 & 3.0276 & 0.082 & 1.508 & .949 & 2.398 \\
\hline & Middle & .6322 & .2885 & 4.796 & 0.028 & 1.88 & 1.069 & 3.342 \\
\hline \multirow{9}{*}{ Region (Ref:Afar) } & Tigray & .292 & .322 & 0.828 & 0.364 & 1.340 & .7127 & 2.519 \\
\hline & Amhara & -.382 & .362 & 1.124 & 0.291 & .682 & 1.335 & 1.386 \\
\hline & Oromia & 1.248 & .336 & 13.764 & 0.000 & 3.494 & 1.801 & 6.740 \\
\hline & Somali & .916 & .334 & 7.50 & 0.006 & 2.498 & 1.296 & 4.812 \\
\hline & Benishangul & .893 & .377 & 5.617 & 0.018 & 2.441 & 1.166 & 5.110 \\
\hline & SNNPR & 1.612 & .410 & 15.445 & 0.000 & 5.108 & 2.244 & 11.199 \\
\hline & Gambela & .746 & .376 & 3.92 & 0.047 & 2.10 & 1.008 & 4.410 \\
\hline & Harari & .557 & .463 & 1.440 & 0.229 & 1.746 & .7041 & 4.33 \\
\hline & DireDawa & 1.530 & .635 & 5.808 & 0.016 & 4.620 & 1.331 & 16.034 \\
\hline \multicolumn{2}{|l|}{ Constant } & -.916 & .477 & 3.686 & 0.055 & & & \\
\hline
\end{tabular}

